\title{
Longitudinal Combustion Instabilities in Ramjet Engines: Identification of Acoustic Modes
}

\author{
James E. Crump* and Klaus C. Schadow $\dagger$ \\ Naval Weapons Center, China Lake, California \\ and \\ Vigor Yangł and Fred E.C. Culick§ \\ California Insitute of Technology, Pasadena, California
}

\begin{abstract}
Longitudinal combustion instabilities in liquid-fueled ramjet engines have been investigated with attention focused on determination of the acoustic mode structures. Detailed pressure measurements, including both amplitude and phase, were made at ten positions spanning the length of the engine. The experimental data have been analyzed using two linear acoustic models. Four distinct modes were observed for various inlet/combustor combinations. These results help identify the mechanisms exciting low-frequency pressure oscillations in ramjet engines.
\end{abstract}

$\mathbf{L}$ ONGITUDINAL pressure oscillations have presented serious problems in recent developments of liquid-fueled ramjet engines. As a consequence of interactions between large-amplitude waves and the inlet shock system, significant losses in engine thrust and performance can occur. In extreme cases, oscillations may reach sufficient amplitude to unstart the inlet.

This paper summarizes the results obtained in a continuing research program devoted to low-frequency combustion instabilities in ramjet engines. ${ }^{1-4}$ Earlier investigations have provided basic information about the inlet shock response, the shock/acoustic wave interaction, and the influences of various operational conditions on pressure oscillations for the research coaxial dump combustor operated at the Naval Weapons Center. The results indicate that 1) fuel droplet breakup and vaporization are not a necessary condition for combustion instability - ethylene and JP-4 behave similarly with respect to the oscillatory fields; 2 ) fuel/air mixing in the shear layer is critical-large-amplitude pressure fluctuations take place only under a rather restricted set of fuel injection conditions and only when the injector is located near the dump plane; and 3) the inlet shock responds to the pressure disturbance in a quasisteady fashion.

The effort reported here is focused on determination of the acoustic modes excited in various combinations of inlet and combustor lengths. Linear acoustical analysis has been used to interpret the experimental data. The purpose is to understand the types of acoustic modes that may be spontaneously generated in ramjet engines. Knowledge of this kind is important for exploring the mechanisms of driving pressure oscillations and for verifying theoretical models.

\section{Experimental Arrangement}

The overall ramjet configuration described in detail in Ref. 2 and shown schematically in Fig. 1 includes a plenum, a win-

Received April 4, 1985; revision received Oct. 14, 1985. This paper is declared a work of the U.S. Government and therefore is in the public domain.

*Senior Physicist, Propulsion Research Branch.

$\dagger$ Head, Propulsion Research Branch.

$\ddagger$ Research Fellow, Jet Propulsion (presently at Pennsylvania State University, University Park, PA). Member AIAA.

§Professor, Jet Propulsion and Applied Physics. Associate Fellow AIAA. dowed convergent/divergent diffuser, a circular inlet duct, and a dump combustor. Heated air is supplied in a connected pipe facility; both gaseous and liquid fuels have been used. The various lengths for the inlet and the combustor and the nominal test conditions are noted in Fig. 2.

Ten pressure tranducers with high-frequency response (Kistler model 202A1) were located along the wall of the engine, as indicated by the arrows in Fig. 1. The transducers were water cooled and attached to the ramjet by means of a $1 / 8$ in. pipe thread adapter that reduced the frequency response of the transducer installation to an estimated $5000 \mathrm{~Hz}$. The pressure signals and reference timing marks were recorded on a 14 track analog tape recorder for subsequent analysis. Measurements were also made of mean pressure and temperature fields in the entire device.

Since the measurement of the relative phase of pressure oscillations is very important for determination of the acoustic mode structure, special care was exercised on phase calibra-

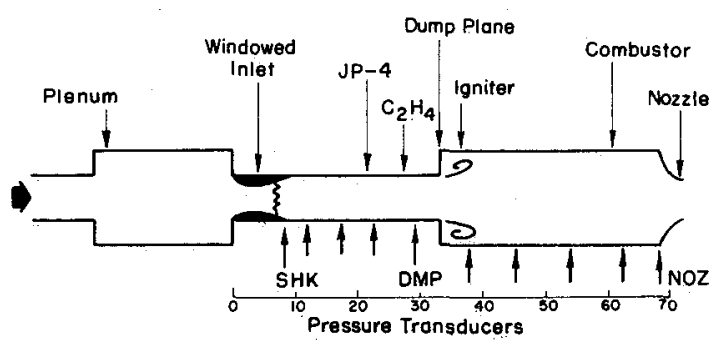

Fig. 1 Physical arrangement of laboratory ramjet engine.

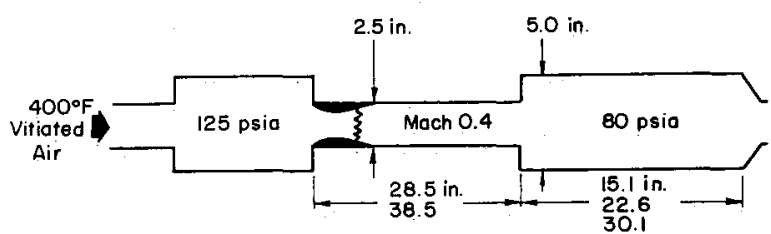

Air Mass Flow : $5.0 \mathrm{LB} / \mathrm{S} \quad \mathrm{C}_{2} \mathrm{H}_{4}$ Moss Flow : $0.155 \mathrm{LB} / \mathrm{S}$ $A / F\left(\mathrm{C}_{2} \mathrm{H}_{4}\right): 34 / 1 \quad J P-4$ Mass Flow: $0.160 \mathrm{LB} / \mathrm{S}$ $A / F(J P-4): 30 / 1$

Fig. 2 Nominal test conditions. 
tion of the transducer/instrument system. The calibration was accomplished in two steps. First, the ten pressure transducers with their output recorded on a cathode ray oscillograph were mounted in a circle around the center of the end cap of a sealed pressure vessel. A squib was then fired along the centerline of the vessel. No measurable phase shift was observed between the transducers in their response to the pressure pulse generated by the squib. Second, a sine wave calibration signal was applied simultaneously to all the transducer amplifier inputs; the outputs were recorded on the tape and played back through band pass filters onto a cathode ray oscillograph. The slight phase shifts from some of the filters were accounted for in the data reduction. The accuracy of the phase measurements for sinusoidal waves was $\pm 6 \mathrm{deg}$. All phase measurements were made with respect to the transducer nearest the combustor nozzle (NOZ).

\section{Typical Test Data}

The time record in Fig. 3 shows the history of the fuel injected in each test run. For approximately the first $1.5 \mathrm{~s}$ of ramjet operation, the fuel was gaseous ethylene, $\mathrm{C}_{2} \mathrm{H}_{4}$. A transition period followed, during which both $\mathrm{C}_{2} \mathrm{H}_{4}$ and JP-4 were burned to ensure ignition of JP-4. The final portion of the test used only JP-4 fuel.

The measured pressure data were routinely analyzed at frequencies up to $5000 \mathrm{~Hz}$. The frequency content of the NOZ transducer signal is shown in Fig. 4 and of the SHK transducer in Fig. 5 . In both figures, the relative amplitudes of the oscillations are scaled to the highest amplitude of the plot. The time window from -0.5 to $0 \mathrm{~s}$ shows the relative ampltitude of oscillations with hot air only. The window from 0 to approximately $1.5 \mathrm{~s}$ corresponds to $\mathrm{C}_{2} \mathrm{H}_{4}$ combustion; the predominant frequency is $500 \mathrm{~Hz}$. During the transition from $\mathrm{C}_{2} \mathrm{H}_{4}$ to JP-4 when both fuels were burning, the dominant frequency was $175 \mathrm{~Hz}$, with the $500 \mathrm{~Hz}$ mode apparently shifting to a somewhat higher frequency of $600 \mathrm{~Hz}$. With JP-4 combustion only for the remainder of the test, the $175 \mathrm{~Hz}$ mode diminished significantly and the $500 \mathrm{~Hz}$ mode was again conspicuous. As noted in Ref. 2. the characteristics of pressure oscillations changed only slightly between the $\mathrm{C}_{2} \mathrm{H}_{4}$ and JP-4 operations.

High-frequency oscillations $(3000-4000 \mathrm{~Hz})$ were also observed in the combustor, similar to the situations in some side-dump ramjet engines. ${ }^{5}$ They are believed to be associated with unstructured vortices produced in the combustor and were not transmitted through the inlet. The conspicuous frequency at $3650 \mathrm{~Hz}$ is close to that of the first tangential mode calculated for the combustion chamber.

\section{Linear Acoustic Analyses}

The measured results for the unsteady flowfield were analyzed using two linear acoustic models. The first is a simple linear stability analysis accommodating both acoustic and enthropy fluctuations. ${ }^{6}$ The engine is approximated by division into two parts: the inlet section and the combustion chamber. Each region is treated separately and then matched with the other at the dump plane. The combustion zone is assumed to be acoustically compact, its unsteady behavior being represented by Crocco's sensitive time-lag hypothesis. ${ }^{7}$ As a first approximation, we assume the mean flowfield to be uniform in each section. The oscillatory field is therefore the superposition of two simple plane acoustic waves running down- and upstream and an entropy wave carried with the mean flow. Combination of these wave equations with the proper boundary conditions at the shock wave and the entrance of the exit nozzle forms a well-posed problem for the unsteady motion.

While this analysis provides reasonable solution for the frequencies and mode shapes, it is seriously incomplete because it does not include, among other things, treatment of the mean flowfield in the combustor. The second model is devoted to

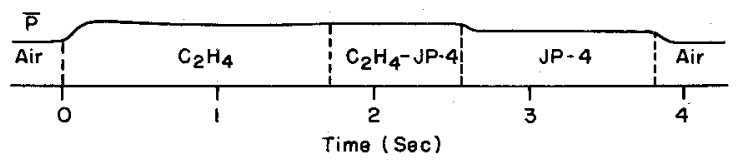

Fig. 3 Typical test record.

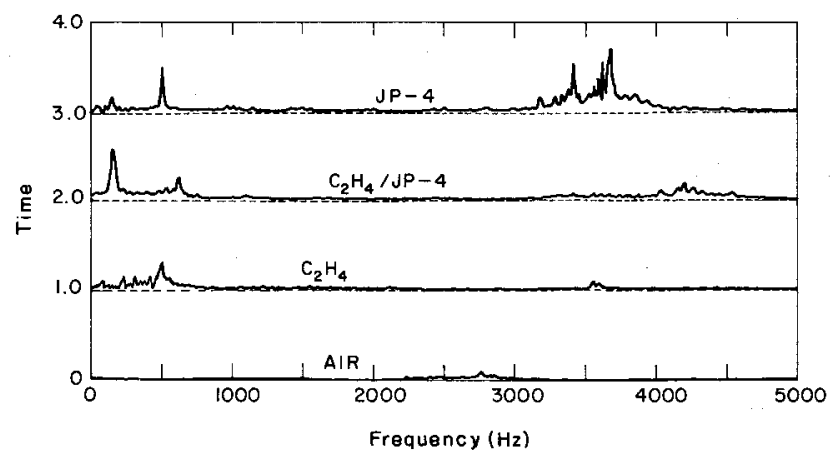

Fig. 4 Frequency content in combustor.

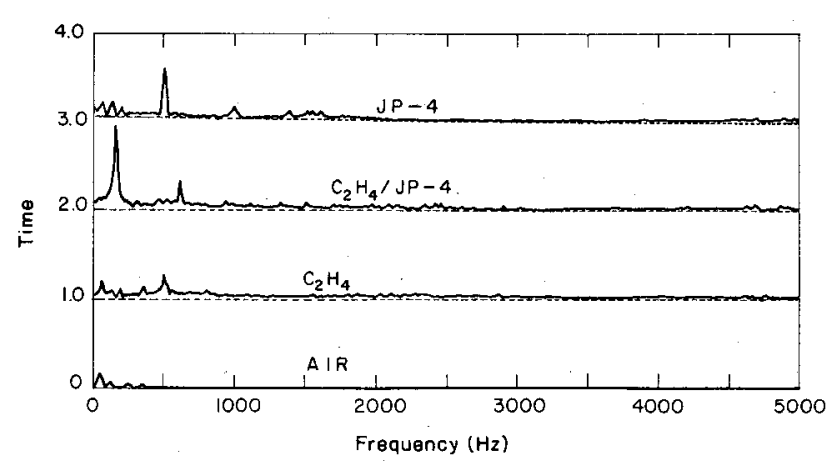

Fig. 5 Frequency content immediately downstream of shock.

correcting this matter with an integral formulation. The procedure is essentially the approach taken in Ref. 8 . It is intended to provide a simple and realistic framework accommodating the fundamental features of the flowfield in the combustor, including the flame front, shear layer, and recirculating flow. For low-frequency oscillations, the flame front and shear layer can be represented adequately by two infinitesimally thin sheets: the flame and vortex sheets, respectively. The flowfield is accordingly decomposed into a flow of reactants, a region containing combustion products, and a recirculation zone. The three zones are then matched at those sheets by taking into account conservation and kinematic relations. Determination of their shapes is part of the solution, The unsteady motions are treated within linear acoustics and approximated as quasi-one-dimensional motion in each region.

Depending on the flow conditions, either one of the above analyses is employed to calculate the acoustic mode structures. The flame sheet model is used for all of the cases except for the transition period from gaseous ethylene to liquid JP-4, during which the combustion processes spread over much of the chamber and no well-defined flame zone exists. We therefore apply the simple model to this situation.

\section{Correlation of Experiments and Analyses}

A series of tests were carried out for the various combinations of inlet and combustor lengths given in Table 1. The number in the matrix is the configuration number referred to subsequently. Four different longitudinal modes have been 


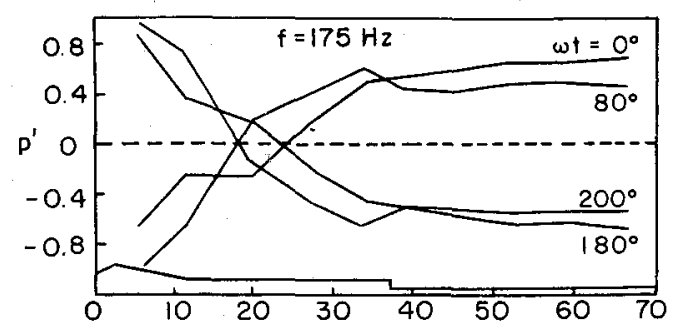

(a) Measured Acoustic Pressure Distributions

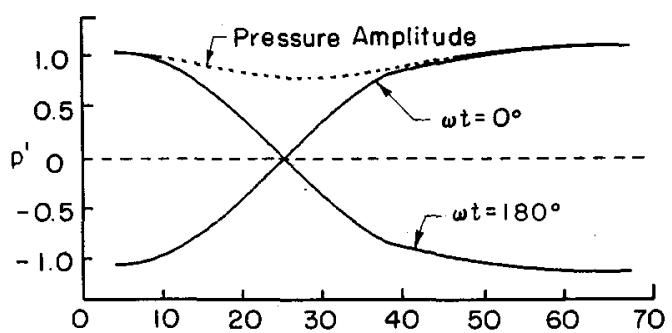

(b) Colculated Acoustic Pressure Distributions

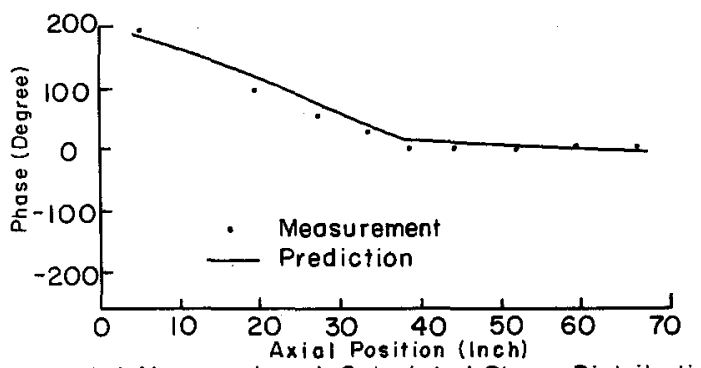

(c) Measured and Calculated Phase Distributions

Fig. 6 Measured and calculated acoustic pressure amplitude and phase distributions (case $1, f=175 \mathrm{~Hz}$, test D-114).

\begin{tabular}{ccc} 
Table 1 & \multicolumn{3}{c}{ Inlet/combustor geometrical combinations } \\
\hline \hline Combustor & \multicolumn{2}{c}{ Inlet lengths, in. } \\
lengths, in. & 38.5 & 28.5 \\
\hline 30.1 & 1 & 4 \\
22.6 & 2 & 5 \\
15.1 & 3 & 6 \\
\hline
\end{tabular}

observed. The general information on each of the modes is summarized in Table 2, including 1) acoustic pressure amplitudes (one-half peak-to-peak value) immediately downstream of the inlet shock (SHK), immediately upstream of the dump plane (DMP), and at the entrance of the exhaust nozzle (NOZ); 2) the fuels being burned (X); and 3) the measured and calculated frequencies. Data from tests D-114, D-163, and D-164 and corresponding results of analysis are given in Figs. 6-9.

Figure $6 \mathrm{a}$ shows the measured acoustic pressure distributions of the $175 \mathrm{~Hz}$ mode of configuration 1 (test D-114) at four different times within one cycle. This case occurs during the period when both ethylene and JP-4 are burning. Figure $6 \mathrm{~b}$ shows the calculated real part of the pressure fluctuations, where the dashed line denotes the envelope of the amplitude distribution. Both the theoretical and experimental amplitudes were normalized to provide easy comparison. The acoustic field in the combustor is a bulk mode with uniform phase distribution. In the inlet section, the phase varies almost linearly as described in Ref. 6 . The pressure amplitude changes only slightly due to the small acoustic reflection coefficient of the shock, its calculated magnitude and phase being respec-

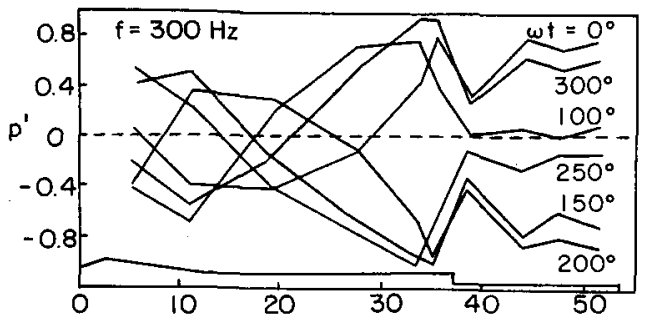

(a) Meosured Acoustic Pressure Distributions

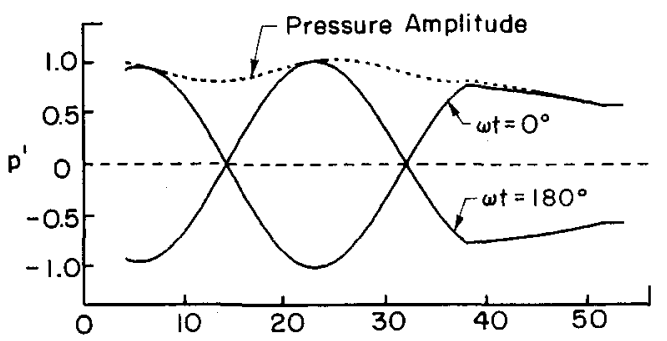

(b) Calculated Acoustic Pressure Distributions

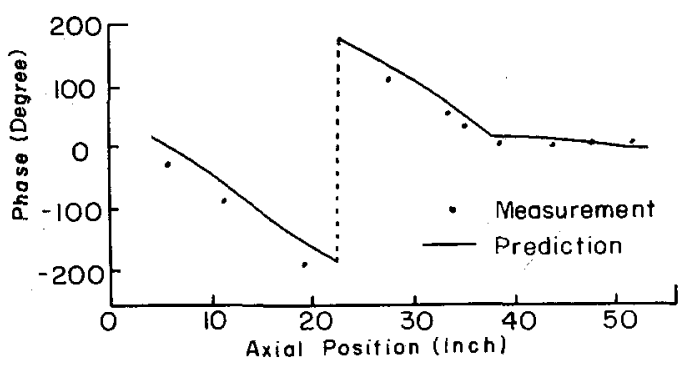

(c) Meosured and Calculated Phase Distributions

Fig. 7 Measured and calculated acoustic pressure amplitude and phase distributions (case $2, f=300 \mathrm{~Hz}$, test D-164).

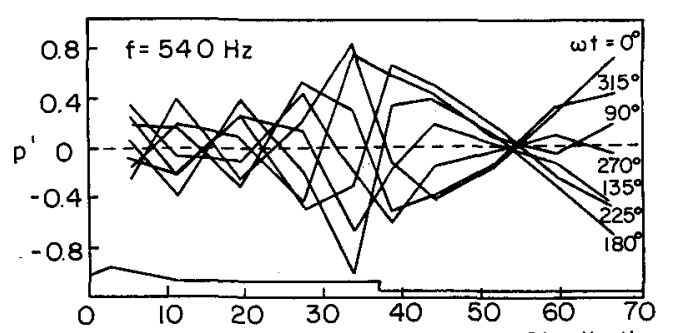

(a) Meosured Acoustic Pressure Distributions

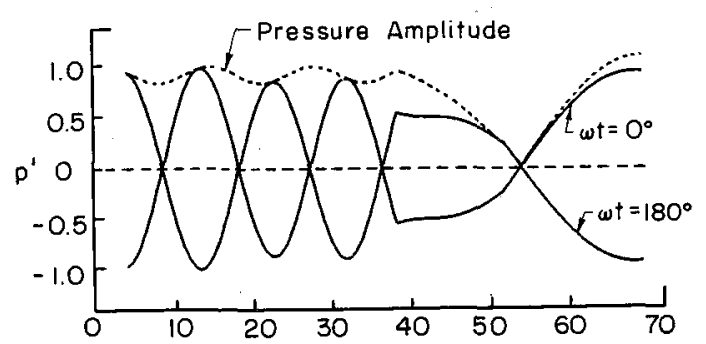

(b) Calculated Acoustic Pressure Distributions

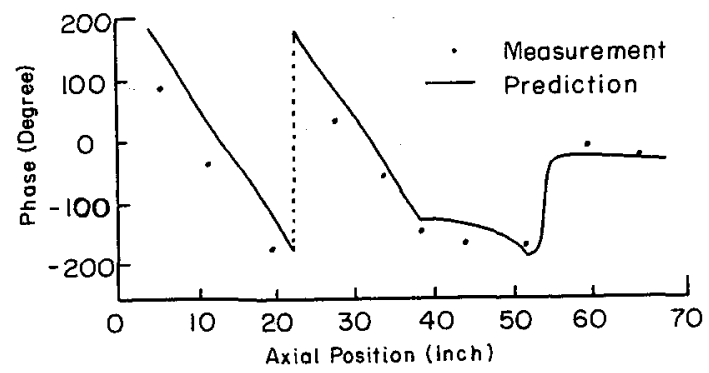

(c) Measured and Calculated Phose Distributions

Fig. 8 Measured and calculated acoustic pressure amplitude and phase distributions (case $3, f=540 \mathrm{~Hz}$, test D-114). 
Table 2 Measured and calculated acoustic modes

\begin{tabular}{|c|c|c|c|c|c|c|c|c|c|}
\hline \multirow[b]{2}{*}{ Config. } & \multirow[b]{2}{*}{ SHK } & \multirow{2}{*}{$\begin{array}{c}\hat{\mathrm{p}}_{\max }, \mathrm{psia} \\
\mathrm{DMP}\end{array}$} & \multirow[b]{2}{*}{$\mathrm{NOZ}$} & \multirow[b]{2}{*}{$\mathrm{E}$} & \multicolumn{2}{|l|}{ Fuel $^{\mathrm{a}}$} & \multicolumn{2}{|c|}{ Freq, $\mathrm{Hz}^{b}$} & \multirow[b]{2}{*}{ Test } \\
\hline & & & & & $\mathrm{E} / \mathrm{J}$ & $\mathrm{J}$ & Expt. & Anal. & \\
\hline 1 & 8 & 5 & 6 & - & $\mathrm{X}$ & - & 175 & 133 & D-114 (Fig. 6) \\
\hline 1 & - & - & - & - & $\mathrm{X}$ & - & 175 & 133 & D-115 \\
\hline 2 & 2 & 2 & 2 & $\mathrm{X}$ & $\mathrm{X}$ & $\mathrm{X}$ & 190 & 160 & D-163 \\
\hline 3 & 7 & 7 & 5 & $\mathrm{X}$ & $\mathrm{X}$ & $\mathrm{X}$ & 300 & 299 & D-164 (Fig. 7 ) \\
\hline 1 & - & - & - & $\mathrm{X}$ & - & $\mathrm{X}$ & 540 & 549 & D-114 (Fig. 8) \\
\hline 1 & 10 & 31 & 22 & $\mathrm{X}$ & - & - & 540 & 549 & D-121 \\
\hline 4 & 11 & 20 & 19 & $\mathrm{X}$ & - & - & 540 & 537 & D-159 \\
\hline 2 & 3 & 8 & 4 & $\mathrm{X}$ & - & $\mathrm{X}$ & 650 & 665 & D-163 (Fig. 9) \\
\hline
\end{tabular}

${ }^{\mathrm{a}} \mathrm{E}=$ Ethylene, $\mathbf{J}-4 .{ }^{\mathrm{b}}$ Expt.$=$ Experimental; Anal. $=$ Analytical.

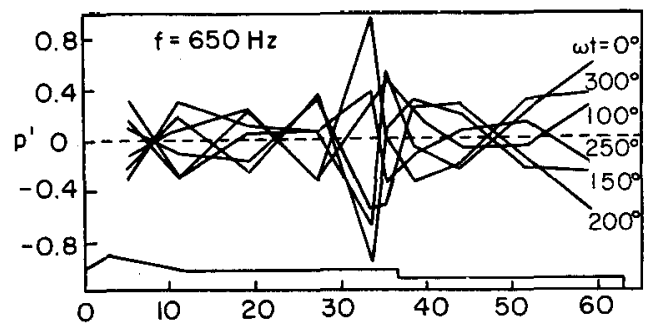

(a) Measured Acoustic Pressure Distributions

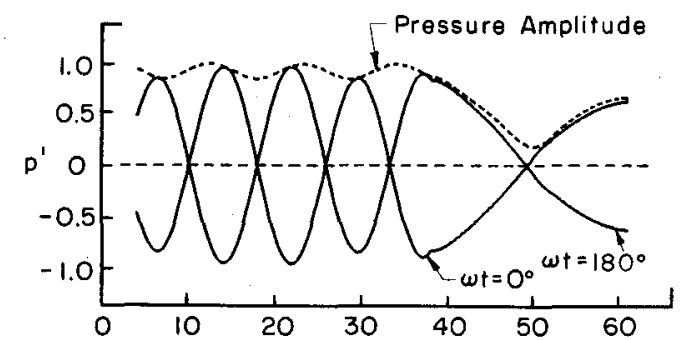

(b) Colculated Acoustic Pressure Distributions

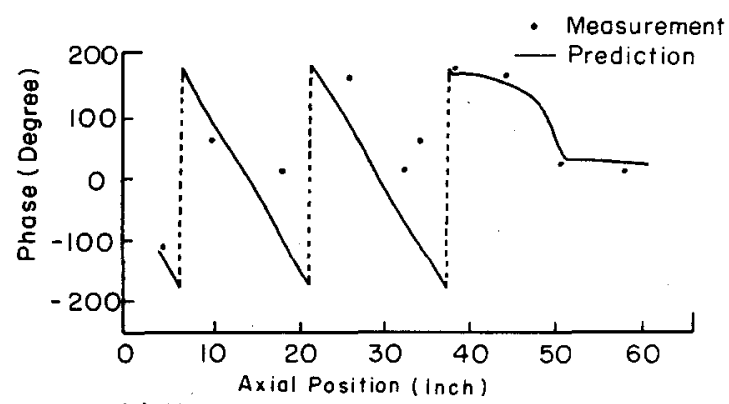

(c) Measured and Calculated Phose Distributions

Fig. 9 Measured and calculated acoustic pressure amplitude and phase distributions (case $4, f=650 \mathrm{~Hz}$, test D-163).

tively 0.14 and $22.5 \mathrm{deg}$ based on an isentropic flow model given in Ref. 9. Thus, the field is dominated by the leftward traveling wave. The entire acoustic field consists of a bulk mode in the combustor and the first longitudinal wave mode in the inlet.

The measured and calculated acoustic pressure and phase distributions for the shortest combustor (configuration 3, test D-164) are shown in Fig. 7. The field consists of a bulk mode in the combustor and the second longitudinal wave mode in the inlet. The presence of the extremes in the envelope of the pressure amplitude profile in the inlet indicates that the wave is a complex standing wave, rather than a traveling one. Each pressure node oscillates around its mean position periodically, no fixed node point being observed.

Figure 8 shows the wave structure of the mode at $540 \mathrm{~Hz}$ (test D-114). This mode is the first longitudinal mode of the combustor with a nonstationary standing wave in the inlet; it
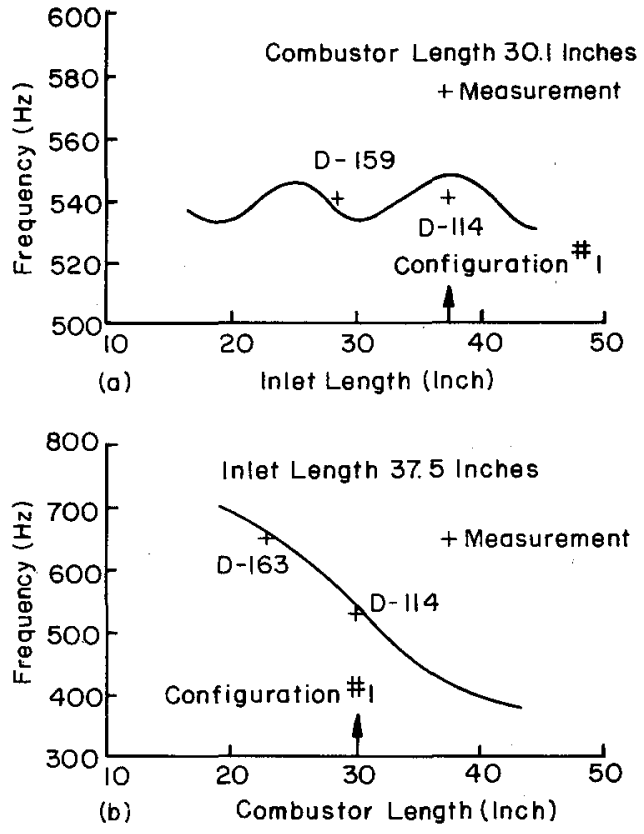

Fig. 10 Dependence of the first longitudinal mode in the combustor on the inlet and combustor lengths.

was observed in the majority of tests. The acoustic field is driven by the pressure oscillations in the combustor and attenuated efficiently by the shock. The mode structure in the combustion chamber is similar to that for a half-wave in a closed-closed pipe. A pressure node exists in the middle of the combustor across which a phase jump of nearly $180 \mathrm{deg}$ occurs. In the inlet section, the waveform is strongly affected by the mean flow and the shock. The influence of the former arises from the Doppler effect, which, together with the smaller speed of sound, causes a reduction of wavelength in comparison with the wave in the combustor. The phase distribution is almost linear because of the efficient absorption of the left-running wave by the shock, as explained previously.

When a short combustor (configuration 2, test D-163) was tested, the dominant oscillation occurred at a frequency of 650 Hz. Figure 9 shows the pressure and phase distributions. The acoustic field in the combustor deviates slightly from the first longitudinal mode for a closed-closed chamber, which would have a frequency of $750 \mathrm{~Hz}$. There is no fixed node. The envelope of the amplitude distribution reaches a nonzero minimum in the middle of the combustor.

To aid identification of the mode structures and the controlling mechanisms, the influences of engine geometry have been calculated for the first longitudinal oscillation under the conditions corresponding to tests D-114, D-159, and D-163. The results are shown in Fig. 10. The calculated frequencies are relatively insensitive to the changes in the inlet length, but decrease almost linearly with the combustor length. The 
limited data are in good agreement, suggesting that the unsteady motion in the engine is determined mainly by the geometry and the flowfield in the combustor. The inlet flow plays a minor role since the shock absorbs effectively the leftrunning acoustic wave generated by the combustion. The contribution of the small amplitude reflected wave to the excitation of pressure oscillations is negligibly small in comparison with that of the combustor flow. The cause for the small humps in Fig. 10a is not clear; they may be due to combined influences of the shock admittance function, the combustion processes, and the effects of engine geometry on the acoustics.

\section{Conclusions}

Four separate axial acoustic modes have been identified in a series of ramjet combustion tests. The frequencies of the oscillations covered a range of $170-650 \mathrm{~Hz}$. The bulk mode oscillations in the combustor occurred mainly when both ethylene and JP-4 were burning or when a short combustor was tested. For combustion in which either ethylene or JP-4 was burned, the dominant mode was the first longitudinal mode in the combustor. The acoustic field depended strongly on the flow conditions in the combustor, the inlet flow playing a minor role due to the effective absorption of acoustic energy by the inlet shock.

An approximate analysis of the acoustics for the chamber has been used with considerable success for interpreting observed behavior. The configuration is divided into two parts: the inlet and the combustion chamber. Accordingly, the acoustic field is determined in two regions and the results are matched at the interface by requiring continuity of mass flow and pressure. The boundary condition at the upstream end of the inlet is set by the linear unsteady behavior of a normal shock; all viscous effects in the diffuser have been ignored. A choked nozzle provides the boundary condition at the exit.

Good agreement between calculations and data has been found over broad conditions for the distributions of amplitude and phase of several modes. Thus, it appears that the global features of the acoustic field are quite insensitive to the modeling of the combustion processes, although the behavior of the inlet shock must be represented at least qualitatively well. That the shock is a strong absorber of acoustic energy for the conditions treated here has considerable influence on the form of the acoustic field in the inlet.

On the other hand, to date we have not had striking success predicting stability, which is indeed sensitive to the representation of combustion processes. Our broad view at this time is that oscillations exist because of the source of energy associated with interaction between the acoustic field and the combustion processes. Losses of energy are provided by the exhaust nozzle and inlet. The balance of losses and gains of energy determines the limiting amplitude of the oscillations, a matter that can be addressed only by nonlinear analyses not yet available.

In conclusion, existing linear analysis appears to be quite capable of predicting the amplitude and phase distributions of the possible modes of oscillation. It is much less successful in predicting whether or not a particular mode will, in fact, be excited and sustained.

\section{Acknowledgments}

The work at the Naval Weapons Center was performed under Air Task A3103100, Element 61153N and Independent Research Funding 2R000-01-01, Element 61152N; the work at the California Institute of Technology was supported by the Air Force Office of Scientific Research, Grant AFOSR80-0265.

\section{References}

${ }^{1}$ Schadow, K.C., Crump, J.E., Derr, R.L., and Heaser, J.S., "Studies of Pressure Oscillations in a Research Dump Combustor A Progress Report," Proceedings of 17th JANNAF Combustion Meeting, Sept. 1980

${ }^{2}$ Crump, J.E., Schadow, K.C., Blomshield, F.S., Bicker, C.J., "Combustion Instability in a Research Dump Combustor: Pressure Oscillations," Proceedings of 18th JANNAF Combustion Meeting, Oct. 1981

${ }^{3}$ Schadow, K.C., Crump, J.E., and Blomshield, F.S., "Combustion Instability in a Research Dump Combustor: Inlet Shock Oscillations," Proceedings of 18th JANNAF Combustion Meeting, Oct. 1981.

${ }^{4}$ Crump, J.E., Schadow, K.C., Blomshield, F.S., Culick, F.E.C., and Yang, V. "Combustion Instability in Dump Combustors: Acoustic Mode Determinations," Proceedings of 19th JANNAF Combustion Meeting, Oct. 1982

${ }^{5}$ Clark, W.H., "Geometric Scale Effects on Combustion Instabilities in a Side-Dump Liquid Fuel Ramjet," Proceedings of 19th JANNAF Combustion Meeting, Oct. 1982

${ }^{6}$ Yang, V., "Pressure Oscillations in Liquid-Fueled Ramjet Engines," Ph.D. Thesis, California Institute of Technology, Pasadena, CA, May 1984.

${ }^{7}$ Crocco, L. and Cheng, S.I., Theory of Combustion Instability in Liquid Propellant Rocket Motors, AGARD No. 8., Butterworths Scientific Publications, London, 1956.

${ }^{8}$ Yang, V. and Culick, F.E.C., "Analysis of Low Frequency Combustion Instabilities in a Laboratory Dump Combustor," Combustion Science and Technology, to be published.

${ }^{9}$ Culick, F.E.C. and Rogers, T., "The Response of Normal Shocks in Diffusers," AIAA Journal, Vol. 21, 1983, pp. 1382-1390. 